\title{
Life insurance: genomic stratification and risk classification
}

\author{
Yann Joly ${ }^{\star, 1}$, Hilary Burton ${ }^{2}$, Bartha Maria Knoppers ${ }^{1}$, Ida Ngueng Feze ${ }^{1}$, Tom Dent ${ }^{2}$, Nora Pashayan ${ }^{3}$, \\ Susmita Chowdhury ${ }^{2}$, William Foulkes ${ }^{1}$, Alison Hall ${ }^{2}$, Pavel Hamet ${ }^{4}$, Nick Kirwan ${ }^{5}$, Angus Macdonald ${ }^{6}$, \\ Jacques Simard ${ }^{7}$ and Ine Van Hoyweghen ${ }^{8}$
}

With the development and increasing accessibility of new genomic tools such as next-generation sequencing, genome-wide association studies, and genomic stratification models, the debate on genetic discrimination in the context of life insurance became even more complex, requiring a review of current practices and the exploration of new scenarios. In this perspective, a multidisciplinary group of international experts representing different interests revisited the genetics and life insurance debate during a 2-day symposium 'Life insurance: breast cancer research and genetic risk prediction seminar' held in Quebec City, Canada on 24 and 25 September 2012. Having reviewed the current legal, social, and ethical issues on the use of genomic information in the context of life insurance, the Expert Group identified four main questions: (1) Have recent developments in genomics and related sciences changed the contours of the genetics and life insurance debate? (2) Are genomic results obtained in a research context relevant for life insurance underwriting? (3) Should predictive risk assessment and risk stratification models based on genomic data also be used for life insurance underwriting? (4) What positive actions could stakeholders in the debate take to alleviate concerns over the use of genomic information by life insurance underwriters? This paper presents a summary of the discussions and the specific action items recommended by the Expert Group. European Journal of Human Genetics (2014) 22, 575-579; doi:10.1038/ejhg.2013.228; published online 16 October 2013

Access to genetic information by life insurers has been a topic of discussion for many years. ${ }^{1}$ The possibility of using genetic data to underwrite an applicant's insurance policy has given rise to concerns about the emergence of 'genetic discrimination'. Genetic discrimination in the field of life insurance is not necessarily illegal in that in insurance underwriting questions about health, family history of disease, or genetic information may constitute legal exceptions to antidiscrimination legislation. ${ }^{2,3}$ Nevertheless, the expression 'genetic discrimination' has acquired public notoriety ${ }^{4}$ and we will use more neutral language in this paper.

Countries including Canada, the United States, Russia, and Japan ${ }^{5}$ have chosen not to adopt laws specifically prohibiting access to genetic data for underwriting by life insurers. ${ }^{6}$ In these countries, life insurance underwriters treat genetic data like other types of medical or lifestyle data. However, a growing number of countries such as Belgium, France, and Norway ${ }^{5}$ have chosen to adopt laws to prevent or limit insurers' access to genetic data for life insurance underwriting. Other countries including Finland and the United Kingdom have developed voluntary arrangements with the industry (ie moratoria) with similar objectives. ${ }^{7}$

Life insurance is a private contract between the policy-holder and the insurer. Its principal role is to provide financial security to the beneficiaries in the event of the insured's death. ${ }^{8}$ Because of this important role, life insurance is often required, or strongly recommended for those seeking loans to acquire primary social goods, like housing or cars. ${ }^{9}$ In Europe, a consequence of the advent of the welfare state is that private insurance has increasingly played a complementary and supplementary role to social insurance by offering additional security and protection to the population. Thus, in this region, insurance is often considered as a social good that allows individuals to live a comfortable life and as a tool to promote social integration. ${ }^{10}$ In other regions of the world, this social role of life insurance is also recognized to a lesser extent. Given this social role, equitable access to life insurance is perceived as a sensitive issue and cases of denial looked upon negatively in popular media. Although documented incidents of denial or of increased premiums on the basis of genetic information have remained limited to the context of a few relatively well known, highly penetrant, familial, adult-onset, genetic conditions, ${ }^{11}$ they have nevertheless generated significant public concern. Fear that insurers will have access to genetic information generated in a clinical or research setting for use in underwriting has been reported by several studies as a reason for non-participation in genetic research or recommended clinical genetic testing. ${ }^{12-14}$

The clinical utility of genetic testing for monogenic disorders such as Huntington disease, and hereditary forms of cancer are well established. ${ }^{15}$ However, genomic risk profiles based on the known common susceptibility variants have limited utility in risk prediction at the individual level, although they could be used for risk stratification in prevention programmes in populations. ${ }^{16}$ Today, a new era of genomic research has made it increasingly affordable to scan the entire genome of an individual. Researchers and physicians

\footnotetext{
${ }^{1}$ Center of Genomics and Policy, McGill University, Montreal, QC, Canada; ${ }^{2} \mathrm{PHG}$ Foundation, Cambridge, UK; ${ }^{3}$ University College London, London, UK; ${ }^{4}$ Centre Hospitalier de I'Université de Montréal, Montreal, QC, Canada; ${ }^{5}$ Association of British Insurers, London, UK; ${ }^{6}$ Heriot-Watt University, Edinburgh, UK; ${ }^{7}$ Laval University, Quebec City, QC, Canada; ${ }^{8}$ Maastricht University, Maastricht, The Netherlands

${ }^{*}$ Correspondence: Professor Y Joly, Center of Genomics and Policy, McGill University, 740 Drive Penfield Avenue, Suite 5200, Montreal, QC H3A 1A5, Canada. Tel: +1 514398 7286; Fax: +1 514398 4829; E-mail: yann.joly@mcgill.ca
} 
can interpret these data together with medical and lifestyle information in the form of sophisticated risk prediction models. ${ }^{17}$ Moreover, improvement in computing technologies coupled with the Internet make predictive information increasingly available, whether through direct-to-consumer marketing of genetic tests, genetic data sharing online communities, or international research database projects. Given these important technological and scientific changes, and their impact on various stakeholders. The term 'stakeholders' is used in this text to refer to the following groups of individuals: actuaries (person who computes insurance risk and premium rates based on statistical data), academic researchers, community representatives, ethics committees, genetic counsellors, genomic researchers, human rights experts, insurers, governmental representatives, non-governmental organisations, patient representatives, physicians, policy makers, popular media, reinsurers (company in charge of calculating the risk and premium amount for insuring a particular customer), research participants, and underwriters (company or person in charge of calculating the risk involved in providing insurance for a particular customer and to decide how much should be paid for the premium). This list is not meant to be exhaustive as relevant new groups may emerge as this topic further develops in the coming years. A multidisciplinary group of international experts representing different interests (hereinafter 'the Expert Group') revisited the genetics and life insurance debate. The following text presents a summary of the issues discussed and the 'Action Items' agreed upon by the Expert Group at the 'Life Insurance, Risk Stratification, and Personalized Medicine Symposium'.

\section{METHODS}

Following substantial research on the ethical, social, and legal issues associated with the use of genetic information in the context of life insurance, $, 1,5,8,10,11$ and additional input on the emerging scientific, medical, and actuarial contexts, ${ }^{18-20}$ we identified four questions for discussion by the Expert Group (The members of this ad hoc International Expert Group on Genomics, Life Insurance and Breast Cancer are listed as authors of the article):

1. Have recent developments in genomics and related sciences changed the contours of the genetics and life insurance debate?

2. Are genomic results obtained in a research context relevant for life insurance underwriting?

3. Should predictive risk assessment and risk stratification models based on genomic data also be used for life insurance underwriting?

4. What positive actions could stakeholders in the debate take to alleviate concerns over the use of genomic information by life insurance underwriters?

Our discussions took place over a 2-day symposium in Quebec City, Canada (24 and 25 September 2012). The first day consisted of plenary presentations on genomics and life insurance by experts from the group representing different viewpoints, expertise, and geographical regions followed by a period of open discussion (see Table 1). On the following day, the Expert Group discussed the four previously identified questions and reached a consensus on possible ways forward presented below.

\section{DISCUSSION}

Have recent developments in genomics and related sciences changed the contours of the genetics and life insurance debate? The increasing availability of next-generation sequencing (NGS) whole-genome/exome reveals probabilistic genomic information from the preconception stage until the end of life of an individual. Although still largely indecipherable and mainly available in the private sector, direct-to-consumer (DTC) genetic testing. DTC products providing whole-genome sequencing are already being sold to consumers by companies such as Illumina Inc. (San Diego, CA, USA)
Table 1 Selected presentations from members of the Expert Group

Life insurance and genomics: clinical perspectives

Dr William Foulkes,

Professor, Department of Human Genetics and Oncology, McGill University Dr Nora Pashayan

Senior Clinical Lecturer, Department of Applied Health Research, University College London

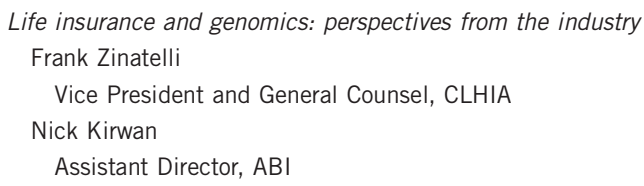

Life insurance and genomics: perspectives from the industry

Frank Zinatelli

Vice President and General Counsel, CLHIA

Nick Kirwan

Assistant Director, $\mathrm{ABI}$

Abbreviations: $\mathrm{ABI}$, Association of British Insurers; CLHIA, Canadian Life and Health Insurance Association.

and Gene By Gene Ltd. (Houston, TX, USA). Rare mutations of unknown impact, as well as clinically significant and actionable incidental findings for common diseases are revealed by NGS and genome-wide association studies (GWAS) ${ }^{21-24}$ Although some of the findings would still be considered research, others could have clinical relevance and involve the possibility of prevention or treatment. Whole-genome/exome results may have a positive impact on insurability as insurance applicants could have the possibility to act proactively on such findings and avoid or forestall, if not treat, potential diseases. Except for some rare or lethal conditions, genetic information may become so commonplace with NGS that, in the absence of rare or lethal conditions (eg Huntington's disease), such information could be treated in the same way as other medical and lifestyle information. ${ }^{25}$ Yet, these new technologies will also generate a vast quantity of data that could be more easily misinterpreted than traditional genetic information and generate incidental findings. ${ }^{26}$

Recent scientific, technical, and social developments have provided research participants and patients with the opportunity to have a more active role in promoting their health status. Genetic data sharing communities, citizen science projects, and IT-enabled interactive consent and governance models in genomics are developing at a rapid pace and could substantially change health research and the delivery of health care. It is essential that all stakeholders in the genetics and insurance debate take account of recent progress in genomics and related sciences so as to inform their perspectives and practices.

Action item 1.1. All stakeholders in the genetic and insurance debate should keep abreast of the most recent developments in genomics and related sciences.

Action item 1.2. The impact on insurability of taking part in online genetic data sharing communities, citizen science projects, and DTC genetic testing should be documented by researchers and made publically available through academic publications or reports.

Action item 1.3. Additional studies regarding the predictive value of genomic information, including GWAS and whole-genome/exome sequencing, should be conducted by clinicians and researchers to clarify and assess its relevance for life insurance underwriting. Stakeholders should be kept informed of the result of such research. 
Are genomic results obtained in a research context relevant for life insurance underwriting?

Genomic results obtained in the research context may not meet scientific and medical requirements (eg analytical validity, clinical validity, and clinical utility/actionability) for use in the clinic. ${ }^{27}$ For this reason, these results and associated information are generally not communicated to research participants. An exception to this general rule is in the field of translational genomic research, which uses the results of preclinical studies to validate new research tools and methods for diagnostic, prevention, and treatment, ${ }^{28}$ and the occasional cases of actionable research results or material incidental findings from GWAS and whole-genome/exome studies. ${ }^{29}$

Given the particular nature of genomic research results, which are generally meant to create generalizable knowledge and the difficulties of interpretation, their use by insurers has raised significant concerns. For example, there is no clear consensus on the scientific criteria and actuarial evidence required for research results to be used for underwriting. Moreover, participants might not even be aware that, in some cases, they may need to declare research results to insurers. Informed of this possibility, individuals could decide (as demonstrated in several studies ${ }^{13,14,30,31}$ ) whether or not to participate in genomic research projects to avoid any negative impact on their insurability. If this phenomenon were to materialize on a large scale, it would also have the effect of stifling scientific research and innovation. Consequently, in many jurisdictions, insurers have been legally precluded or have voluntarily refrained from accessing genetic results including genomic research results. ${ }^{7}$ Given this trend, a broad international consensus among life insurers not to request genomic research results would be a meaningful affirmation. It would effectively promote public trust in the practices of the life insurance industry, foster research participation, and ultimately contribute to the generation and circulation of more medical and actuarial data (statistical information used to calculate insurance risk and premium amount)

Action item 2.1. Where countries have not already adopted laws or moratoria restricting the use of genetic information for life insurance underwriting, life insurers and their member companies should adopt an explicit policy not to ask insurance applicants for genomic research results.

Action item 2.2. Concomitantly, associations of life insurers and reinsurers should consider drafting an international consensus statement recommending to their members not to ask insurance applicants for genomic research results.

\section{Should predictive risk assessment and risk stratification models} based on genomic data be used for life insurance underwriting? Medical risk prediction models estimate the likelihood of future health-related events. These models use information from multiple sources including lifestyle questionnaires as well as the results of a physical examination and blood tests to predict the risk of conditions such as cancer, heart disease, and diabetes. ${ }^{32,33}$ Risk stratification models go further, using these estimates to allocate individuals to deciles or quintiles of the risk distribution or into categorical groups of low-, intermediate-, or high-risks groups. In this way, individuals can then be placed in a segment or risk class alongside others at similar risk. The smaller the stratum, the more alike members of the group will be. Using these models, different interventions can be targeted to different risk strata to potentially improve outcomes.
In life insurance underwriting, individuals having similar risk profiles, for example, for mortality, are grouped together into homogeneous risk classes for the purposes of determining insurance premiums and estimating death benefit costs. ${ }^{34}$ Similar to risk stratification in the medical context, but focusing on mortality, the process of risk classification consists of placing insurance applicants into groups representing roughly equivalent levels of risk. The American Academy of Actuaries maintains that risk classification 'should accurately reflect the cost of a given risk characteristic; be applied objectively and consistently; and be cost-effective and responsive to change (and scientific developments). ${ }^{35}$ If permitted, actuarial risk stratification models integrating genetic data from population biobank projects with other medical data (eg from clinical trials and cohort studies) would have the potential to refine and determine sub-populations for more accurate risk assessment. ${ }^{36}$ Genomic risk stratification, like other contextual medical, environmental, and lifestyle information, could thereby avoid genetic exceptionalism. Ultimately, it could be argued that the absence of genomic risk stratification in insurance underwriting might eventually constitute discrimination due to actuarial/clinical inaccuracy.

Nonetheless, to authorize this approach would require substantial change to be made to the laws and practices of a number of countries, which have already adopted laws or voluntary agreements hoping to neutralize public anxiety about genetic discrimination without excessively disadvantaging insurers. Any change would generate additional costs, and might well foster greater public distrust of insurers even though such classification could eventually become more accurate from an actuarial standpoint.

Currently, insurers routinely place about $90 \%$ of applicants in the standard risk pool. ${ }^{8}$ Few applicants would move into or out of standard risk pools because genomic information about currently known common variants seldom substantially affects mortality risk estimation already based on phenotype and family history. ${ }^{37}$ Furthermore, the accuracy of risk prediction models depends on the target population. Whatever the objective impact of the use of risk prediction models including genetic information for life insurance, enquiries by insurers may well be seen by the public as unwelcome and intrusive. Unless the benefits of insurers' access to genomic information are large and understood, the damage to the public profile of insurers from insisting on access to such information for underwriting may outweigh its current commercial value.

Action item 3.1. Given the current scientific uncertainties and public apprehension, there is at present insufficient benefit to warrant the addition of predictive genomic data to actuarial risk stratification models. However, research by insurance companies on ways to include genomic data to their models and the implication for customer's insurability should be encouraged.

Action item 3.2. To foster public trust in genomics and promote the eventual use of risk prediction and stratification models, insurers should at minimum offer life insurance policy covering a minimal (ceiling) amount at an affordable rate and with no health questions (including about genomics) asked.

What other actions could insurance companies and other stakeholders in the debate take to alleviate concerns over the use of genomic information in life insurance contracts?

Use of genetic information by insurers seems to be one of the recurring factors that motivate people not to participate in genetic 
research or not to undertake clinically relevant genetic testing. ${ }^{13,14}$ For example, in a recent survey prepared for the Office of the Privacy Commissioner of Canada, 52\% of surveyed Canadians expressed strong concern that, if their doctor recommended that they undergo genetic testing, they might be asked to provide the results for nonhealth-related purposes. Seventy-one percent of those who expressed significant concern said their concerns would likely affect their willingness to undergo genetic testing. ${ }^{38}$ This is highly problematic as important decisions regarding one's health care or financial planning should not be taken based on inaccuracies, hype, or anecdotes. Therefore, insurability concerns should be addressed to avoid potentially detrimental effects on research as well as to ensure the integration of genomics into clinical care. Previous attempts by insurers to provide information about the nature and functioning of the life insurance contract have had limited success in reassuring the population. ${ }^{39-41}$ More creative solutions are needed. It could be that the information provided so far has failed to reach most participants in the genomic and insurance debate such as the popular media, ethics committees, clinicians, researchers, and genetic counsellors. The content of the message sent to these stakeholders might also need to be revised and validated by parties representing different complementary expertises in the debate. There is a need for tailored, accessible, and objective information for communication to these stakeholders.

Additional strategies proposed to allay popular anxiety include documenting the industry's experience with genetic information and making this documentation available for independent audits as is currently done in the United Kingdom, ${ }^{7}$ or appointing an independent authority (ie ombudsman) that will be responsible of informing and protecting the population in case of adverse decisions based on genetic data.

Action item 4.1. Groups with complementary expertise (eg insurers, actuaries, genetic counsellors, clinicians, and genomics researchers) should develop clear, up-to-date, reliable information material and frequently asked questions about genomics and underwriting to be communicated by all stakeholders involved (eg public, popular media, ethics committees, clinicians, researchers, and genetic counsellors).

Action item 4.2. Beyond the provision of information, regional/ national life insurance professional organizations could develop openly accessible reference documents regarding the practices of their members on the use of genetic test information. They could also perform regular audits of these practices and have an independent third party also do so.

Action item 4.3. National governments could name an independent third party (ombudsman), with expertise in both genomics and personal insurance underwriting to be responsible for addressing complaints of adverse underwriting decisions involving genomic information.

\section{CONCLUSION}

Genomic research has led to the rapid development of new tools that provide an increasing amount of complex 'at-risk' health information. These recent developments in genomics and concomitant progress in information technologies are presenting a different set of challenges and opportunities for all stakeholders including the life insurance industry. Having reviewed the current ethical, social, and legal issues on the use of genomic information in the context of life insurance, the Expert Group identified four questions and provided action items as a response.
We believe the proposed actions to be sufficiently broad and inclusive to be relevant to life insurance and genomics in a variety of national and regional contexts. They map out interesting options to meet the challenges set forth by the use of genomic information in the context of life insurance. Nevertheless, the evolving pace of the use of genomic data should continue to be carefully monitored by all stakeholders.

The authors are members of the International Expert Group on Genomics, Life Insurance, and Breast Cancer co-chaired by Hilary Burton and Yann Joly.

\section{ACKNOWLEDGEMENTS}

We thank Marie-Cécile Symons and Nadine Thorsen for their valuable assistance in organizing the 'Life Insurance: Breast Cancer Research and Genetic Risk Prediction Seminar' held on 24 and 25 September 2012 in Quebec City. This research was financially supported by the Canadian Institutes of Health Research (CIHR) for the 'CIHR Team in Familial Risk of Breast Cancer' Program (Grant No. 87521) and by the Ministry of Economic Development, Innovation, and Export Trade (Grant No. PSR-S11R1-701).

1 Knoppers BM, Godard B, Joly Y: Life insurance and genetics: a comparative international overview. In: Rothstein MA (ed.) Genetics and Life Insurance: Medical Underwriting and Social Policy. Cambridge, MA, USA: MIT Press, 2004; pp 173-194.

2 Lemmens T, Joly Y, Knoppers BM: Genetic and life insurance: a comparative analysis. GenEdit 2004; 2: 1-15.

3 Zurich Insurance Co. v. Ontario (Human Rights Commission): [1992] 2 S.C.R. 321.

4 Rothstein MA, Anderlik MR: What is genetic discrimination, and when and how can it be prevented? Genet Med 2001; 3: 354-358.

5 Rothstein MA, Joly Y: Genetic information and insurance underwriting: contemporary issues and approaches in the global economy insurance. In: Atkinson P, Glasner P, Lock M (eds) Handbook of Genetics and Society: Mapping the New Genomic Era. London, UK and New York, NY, USA: Routledge, 2009

6 Prince A: Regulation of Genetic Information in Life, Long Term Care, and Disability Insurances: 50 States SurveyAvailable at: https://www.disabilityrightslegalcenter.org/ about/documents/GeneticsStateSurveyFinal.pdf: Cancer Legal Resource Center, 2012 (Last accessed 11 March 2013).

7 Otlowski M, Taylor S, Bombard Y: Genetic discrimination: international perspectives. Annu Rev Genomics Hum Genet 2012; 13: 1-6, 22.

8 Knoppers BM, Joly Y: Physicians, genetics and life insurance. Canad Med Assoc J 2004; 170: 1421-1423.

9 0'Neil M: Genetic information, life insurance and social justice. Monist 2006; 89: 567-592.

10 Council of Europe. Consultation document on predictivity, genetic testing and insurance. In: (CDBI) SCoB (ed.): DH-BIO/INF (2012)1, 2012.

11 Joly Y, Ngueng Feze I, Simard J: Genetic discrimination and life insurance: a systematic review of the evidence. BMC Med 2013; 11: 25

12 Armstrong K, Weber B, FitzGerald G et al: Life insurance and breast cancer risk assessment: adverse selection, genetic testing decisions, and discrimination. Am J Med Genet 2003; 120A: 359-364

13 Godard B, Pratte A, Dumont M, Simard-Lebrun A, Simard J: Factors associated with an individual's decision to withdraw from genetic testing for breast and ovarian cancer susceptibility: implications for counseling. Genet Test 2007; 11: 45-54.

14 Kirkland SA, Raina PS, Wolfson $\mathrm{C}$ et al: Exploring the acceptability and feasibility of conducting a large longitudinal population-based study in Canada. Canad J Aging 2009; 28: 231-242.

15 Becker F, Van EI CG, Ibarreta D et al: Genetic testing and common disorders in a public health framework: how to assess relevance and possibilities. Eur J Hum Genet 2001; 19: S6-S44.

16 Pashayan N, Pharoah P: Translating genomics into improved population screening hype or hope? Hum Genet 2011; 130: 19-21.

17 Freedman AN, Seminara D, Gail MH et al: Cancer risk prediction models: a workshop on development, evaluation, and application. J Nat/ Cancer Inst 2005; 97: 715-723.

18 Burton H: Genetics and Mainstream Medicine: Service Development and Integration. Cambridge, UK: PHG Foundation, 2011.

19 Pashayan N, Duffy S, Chowdhury S et al: Polygenic susceptibility to prostate and breast cancer: implications for personalised screening. Br J Cancer 2011; 104 $1656-1663$.

20 Macdonald AS, Yu F: The impact of genetic information on the insurance industry: conclusion from the 'bottom-up' modeling programme. ASTIN Bull 2011; 41: 343-376.

21 Zimmern RL, Khoury MJ: The impact of genomics on public health practice: the case for change. Public Health Genom 2012; 15: 118-124. 
22 Speicher MR, GeigI JB, Tomlinson IP: FRCPath: effect of genome-wide association studies, direct-to-consumer genetic testing, and high-speed sequencing technologies on predictive genetic counselling for cancer risk. Lancet Oncol 2010; 11: 890-898.

23 Ilumina: Applications/SNP Genotyping and CNV Analysis - Whole-Genome Genotyping and Copy Number Variation AnalysisAvailable at: www.illumina.com/applications/ details/sequencing/dna sequencing.ilmn (Last accessed 11 March 2013).

24 Gene By Gene: DNA DTC - Next-Generation SequencingAvailable at: http://www. dnadtc.com/ (Last accessed 11 March 2013).

25 Drmanac R: The advent of personal genome sequencing. Genet Med 2011; 13 : 188-190.

26 Biesecker LG, Burke W, Kohane I, Plon SE, Zimmern R: Next-generation sequencing in the clinic: are we ready? Nat Rev Genet 2012; 13: 818-824.

27 Dressler LG: Disclosure of research results from cancer genomic studies: state of the science. Clin Cancer Res 2009; 4270-4276.

28 Khoury MJ, Gwinn M, Yoon PW, Dowling N, Moore CA, Bradley L: The continuum of translation research in genomic medicine: how can we accelerate the appropriate integration of human genome discoveries into health care and disease prevention? Genet Med 2007; 9: 665-674.

29 Wolf SM, Crock BN, Van Ness B et al: Managing incidental findings and research results in genomic research involving biobanks and archived data sets. Genet Med 2012; 14: 361-384.

30 Government of Canada: Public Opinion Research Into Genetic Privacy Issues. Ottawa, Canada: Pollara Research and Earnscliffe Research and Communications, 2003.

31 Keogh LA, van Vliet CM, Studdert DM et al: Is uptake of genetic testing for colorectal cancer influenced by knowledge of insurance implications? Med J Aust 2009; 191: 255-258.

32 Nakayama M, Osaki S, Shimokawa $\mathrm{H}$ : Validation of mortality risk stratification models for cardiovascular disease. Am J cardiol 2011; 108: 391-396.
33 Pharoah PDP, Antoniou AC, Easton DF, Ponder BAJ: Polygenes, risk prediction, and targeted prevention of breast cancer. N Engl J Med 2008; 358: 2796-2803.

34 Macdonald A, Mclvor K: Application of a polygenic model of breast and ovarian cancer to critical illness insurance. Ann Actuarl Sci 2006; 1: 319-343.

35 American Academy of Actuaries. Risk classification in voluntary life insurance. Issue Brief 1997; SPRING 1997: 1-4.

36 Holland S, Heidenreich W, Itskovich I: Stratifying long-term care risk by cardiovascular risk factor - an analysis of claims experience with atrial fibrillation. J Insur Med 2006; 38: 253-258.

37 Macdonald AS: Genetic Factors in Life Insurance: Actuarial Basis: Encyclopedia of Life Science (ELS). Chichester, UK: Wiley, 2009.

38 Phoenix Strategic Perspectives Inc.: Survey of Canadians on Privacy-Related Issues. Ottawa, Canada: Office of the Privacy Commissioner of Canada, 2013.

39 Van Hoyweghen I: Taming the wild life of genes by law? Genes reconfiguring solidarity in private insurance. N Genet Soc 2010; 29: 431-455.

40 Geelen E, Horstman K, Marcelis CL, Doevendans PA, Van Hoyweghen I: Unravelling fears of genetic discrimination: an exploratory study of Ducth HCM families in an era of genetic non-discrimination acts. Eur J Hum Genet 2012; 20: 1018-1023.

41 Van Hoyweghen I, Rebert L: Your genes in insurance: from genetic discrimination to genomics solidarity. Person Med 2012; 9: 871-877.

cc) (i) $(\Theta)$ This work is licensed under a Creative Commons Attribution-NonCommercial-NoDerivs 3.0 Unported License. To view a copy of this license, visit http://creativecommons. org/licenses/by-nc-nd/3.0/ 